\title{
Comunicação
}

\section{Adubação foliar com silício na cultura do milho}

Lucas Barbosa de Freitas ${ }^{1}$; Elson Martins Coelho ${ }^{2}$; Suelen Cristina Mendonça Maia ${ }^{3}$; Tiago Roque Benetoli Silva

\section{RESUMO}

Inúmeros trabalhos têm demonstrado o efeito benéfico da adubação com silício sobre o acréscimo da produção de diversas culturas, como, por exemplo, arroz, cana-de-açúcar e batata. No entanto, são escassas as informações sobre os benefícios nutricionais do silício para a cultura do milho. Desta maneira, objetivou-se, neste estudo, avaliar o efeito de doses e épocas de aplicação de silício, via foliar, nas características agronômicas e na produtividade do milho, cultivado no ano agrícola 2007/2008. O delineamento experimental adotado foi o de blocos casualizados, em esquema fatorial $\left(4\right.$ x 3) + 1, com quatro repetições, envolvendo doses de silício $\left(130,260,390\right.$ e $520 \mathrm{~g} \mathrm{ha}^{-1}$ de $\left.\mathrm{Si}\right)$ aplicadas via foliar, épocas de aplicação (2, 5 e 8 folhas expandidas) e uma testemunha (sem aplicação de Si). As variáveis analisadas foram altura das plantas e a inserção da primeira espiga, diâmetro de colmo, índice de clorofila foliar, teor foliar de silício, número de grãos por espiga, massa de 100 grãos e produtividade de grãos. O silício aplicado via foliar influenciou somente o teor foliar de Si.

Palavras-chave: Doses, épocas de aplicação e teor foliar.

\section{ABSTRACT}

\section{Foliar fertilization with silicon in maize}

Numerous studies have shown the beneficial effect of silicon on increased production of several crops, such as sugar cane, rice and potato. However, there is little information about the nutritional benefits of silicon on maize. Thus, the aim of this study was to evaluate the effect of doses and timing of silicon leaf application on the agronomic characteristics and grain yield of maize grown in the agricultural year 2007/2008. The experiment was arranged in a randomized block design in a factorial scheme $(4 \times 3)+1$, with four replications, involving doses of silicon (130, 260,390 and $520 \mathrm{~g} \mathrm{ha}^{-1}$ ) by foliar application, time of application (2, 5 and 8 expanded leaves) and a control (without silicon application). The studied variables included: plant height, height of first ear, stem diameter, leaf chlorophyll content, leaf silicon content, number of grains per ear, weight of 100 grains and grain yield. Silicon supplemented via foliar application influenced only the variable leaf silicon content.

Key words: Doses, time of application and nutrient leaf content.

\footnotetext{
Recebido para publicação em março de 2010 e aprovado em abril de 2011

${ }^{1}$ Engenheiro -Agrônomo, Mestrando em Agricultura, Departamento de Recursos Naturais - Ciência do Solo, Faculdade de Ciências Agronômicas/FCA, Universidade Estadual Paulista/UNESP, Caixa Postal 237, 18603-970, Botucatu,SP, Brasil. lucasbf@ fca.unesp.br

${ }^{2}$ Zootecnista, Doutor, Departamento de Zootecnia, Centro de Educação Superior Norte do Rio Grande do Sul, Universidade Federal de Santa Maria, Av. Independência, 3751 Bairro Vista Alegre, 98300-000, Palmeira das Missões, RS, Brasil. elsoncoelho@smail.ufsm.br

${ }^{3}$ Engenheira-Agrônoma, Mestranda em Agricultura, Departamento de Produção Vegetal, Faculdade de Ciência Agronômicas/FCA, Universidade Estadual Paulista/UNESP, , Caixa Postal 237, 18603-970, Botucatu, SP, Brasil. suelen.maia@fca.unesp.br

${ }^{4}$ Engenheiro-Agrônomo, Doutor, Campus Regional de Umuarama, Universidade Estadual de Maringá, Caixa Postal 65, 87501-970. Umuarama, PR. trbsilva@uem.br
} 


\section{INTRODUÇÃO}

O silício ( $\mathrm{Si}$ ) não é considerado elemento essencial às plantas superiores; contudo, vários trabalhos têm mostrado o efeito benéfico desse elemento sobre o aumento da produção de diversas culturas como, por exemplo, arroz (Mauad et al., 2003a; Pereira et al., 2004; Camargo et al., 2007); cana-de-açúcar (Savant et al., 1999; Madeiros et al., 2009) e batata (Pulz et al., 2008) dentre outras.

A absorção do Si confere benefícios às culturas, tais como: aumento da resistência ao acamamento e da eficiência fotossintética (Deren, 2001). Também ameniza toxidez de $\mathrm{Fe}, \mathrm{Mn}, \mathrm{Al}$ e $\mathrm{Na}$ e estimula a produção de fitoalexinas (fenóis) (Korndörfer et al., 1999a). O silício é um elemento químico envolvido em funções físicas de regulagem da evapotranspiração e é capaz de formar uma barreira de resistência mecânica à invasão de fungos e bactérias para o interior da planta, dificultando, também, o ataque de insetos praga (Epstein, 2001; Melo et al., 2003; Costa et al., 2009). O efeito da proteção mecânica é atribuído, principalmente, ao depósito de silício, na forma de sílica amorfa $\left(\mathrm{SiO}_{2} \cdot \mathrm{nH}_{2} \mathrm{O}\right)$, na parede celular. A acumulação de silício nos estomas provoca a formação de uma dupla camada de sílica cuticular, a qual, pela redução da transpiração (Datnof et al., 2001), faz com que a exigência de água pelas plantas seja menor. Isso pode ser de extrema importância para as plantas que crescem em solos de clima tropical, onde estão sujeitas a veranicos.

A forma de fornecimento de Si para as plantas vem sendo estudada, recentemente, a partir da liberação do uso do silicato de potássio como fertilizante. Até então, o Si era fornecido para as plantas somente via uso de escórias de siderurgia, na forma de silicatos de cálcio e magnésio, os quais são fontes de baixíssima solubilidade em água e que, dependendo da origem, podem apresentar traços de metais pesados. Dessa forma, o silicato de potássio é uma fonte interessante de fornecimento de $\mathrm{Si}$, que, aplicado via foliar, pode facilitar o aproveitamento desse elemento pelas plantas, além de poder ser aplicado em conjunto com fungicidas e inseticidas, economizando-se, assim, em aplicações.

O silicato de potássio é originário da fusão, em alta temperatura e pressão, da sílica (quartzo finamente moído), com hidróxido de potássio e, ou, carbonato de potássio. No mercado, existem diferentes silicatos de potássio, com diferentes garantias de potássio $(\mathrm{K})$ e $\mathrm{Si}$; no entanto, de maneira geral, são produtos totalmente solúveis em água, de alto $\mathrm{pH}(12)$, densos $\left(\mathrm{d}=1,4 \mathrm{~g} \mathrm{~cm}^{-3}\right)$, com teores médios de $\mathrm{Si}$ de 10 a $12,2 \%$ e de 10 a $15 \%$ de $\mathrm{K}_{2} \mathrm{O}$.

A escassez de informações sobre o uso de Si na cultura do milho justificou o presente trabalho. Assim, objetivou-se, neste estudo, avaliar o efeito de doses e épocas de aplicação de silício, por via foliar, nas características agronômicas e produtividade de grãos do milho.

\section{MATERIAL E MÉTODOS}

O experimento foi conduzido no ano agrícola 2007/ 2008, em área experimental pertencente à Universidade Estadual de Mato Grosso do Sul (UEMS), Unidade Universitária de Cassilândia, MS, localizada a $19^{\circ} 05^{\prime} \mathrm{S}$ e $51^{\circ}$ 56' W e altitude de $471 \mathrm{~m}$. Os dados de precipitação, obtidos durante a condução do experimento, apresentam-se na Figura 1, caracterizando um ano típico da região, em termos climáticos, chuvoso e sem ocorrência de veranicos.

O solo do local foi classificado como NEOSSOLO QUARTZARÊNICO (EMBRAPA, 1999), textura arenosa, cujos atributos químicos avaliados antes da instalação do experimento, na profundidade de $0-20 \mathrm{~cm}$, apresenta$\operatorname{ram} 14,3 \mathrm{mg} \mathrm{dm}^{-3}$ de fósforo; $11,07 \mathrm{~g} \mathrm{~kg}^{-1} \mathrm{de} \mathrm{MO} ; 5,51 \mathrm{pH}$ em $\mathrm{CaCl}_{2} ; 0,18 ; 1,2 ; 0,55 ; 2,05 ; 3,98 \mathrm{cmol}_{\mathrm{c}} \mathrm{dm}^{-3} \mathrm{de} \mathrm{K}, \mathrm{Ca}$, $\mathrm{Mg}, \mathrm{H}+\mathrm{Al}$ e capacidade de troca de cátions (CTC), respectivamente. $\mathrm{O}$ grau de saturação de bases $(\mathrm{V})$ foi de $48,49 \%$.

Adotou-se o delineamento experimental de blocos casualizados, em esquema fatorial $(4 \times 3)+1$, com quatro repetições, totalizando 52 parcelas. Os tratamentos foram constituídos por quatro doses de silício $(130,260,390$ e $520 \mathrm{~g} \mathrm{ha}^{-1} \mathrm{de} \mathrm{Si}$ ), aplicadas via foliar, combinadas com três épocas de aplicação (plantas apresentando 2, 5 e 8 folhas expandidas) e uma testemunha (sem aplicação de Si). A fonte de silício foi o silicato de potássio, contendo $12 \%$ de $\mathrm{Si}$ e $15 \%$ de $\mathrm{K}_{2} \mathrm{O}$. Foi realizado um balanceamento, adicionando-se $10 \mathrm{~kg} \mathrm{ha}^{-1}$ a mais de $\mathrm{K}_{2} \mathrm{O}$, na adubação de plantio, de forma a evitar que o potássio presente no silicato influenciasse nos resultados.

As parcelas experimentais foram constituídas de 6 fileiras de 5,0 metros (m) de comprimento e 4,8 $\mathrm{m}$ de largura $\left(24 \mathrm{~m}^{2}\right)$, considerando-se como área útil as 2 fileiras centrais. O espaçamento entrelinhas foi de $0,80 \mathrm{~m}$, com uma população de 55000 plantas por hectare.

Foi realizado preparo de solo, inicialmente com grade pesada e, posteriormente com grade leve, tendo-se, como objetivo, nivelar o terreno para a semeadura. A semeadura do milho (híbrido simples AG 8021) foi realizada em 10 de Novembro de 2007, com semeadora-adubadora tracionada por trator. Conforme o resultado da análise química da camada superficial do solo e baseando-se nas recomendações de Raij et al. (1997) aplicaram-se as seguintes doses de nutrientes na semeadura: 30,70 e 50 $\mathrm{kg} \mathrm{ha}^{-1}$ de N, $\mathrm{P}_{2} \mathrm{O}_{5}$ e $\mathrm{K}_{2} \mathrm{O}$, respectivamente, e foram adicionados mais $10 \mathrm{~kg}^{-1} \mathrm{de}_{2} \mathrm{O}$ para o balanceamento. Utilizou-se, como fonte de $\mathrm{N}, \mathrm{P}_{2} \mathrm{O}_{5}$ e $\mathrm{K}_{2} \mathrm{O}$, respectivamente, ureia ( $45 \%$ de $\mathrm{N}$ ), superfosfato simples ( $18 \%$ de $\mathrm{P}_{2} \mathrm{O}_{5}$ e $12 \%$ de S) e cloreto de potássio $\left(60 \%\right.$ de $\left.\mathrm{K}_{2} \mathrm{O}\right)$. Foram aplicados também de $90 \mathrm{~kg} \mathrm{ha}^{-1} \mathrm{de} \mathrm{N}$ em cobertura (Raij et al., 1997). A fonte de $\mathrm{N}$ foi o sulfato de amônio (20\% de N e 24\% de S). 
Para as aplicações dos tratamentos com Si, utilizouse pulverizador costal, com capacidade para $10 \mathrm{~L}$, com vazão regulada de maneira a proporcionar o mesmo volume em cada aplicação, sendo o volume de calda utilizado de $300 \mathrm{~L} \mathrm{ha}^{-1}$. A aplicação do Si, referente às épocas de 2,5 e 8 folhas completamente expandidas, foram realizadas, respectivamente, aos 3, 13, e 20 dias após a emergência (DAE).

No dia 27 de março de 2008, foi feita a colheita manual das plantas contidas na área útil e, também, coletadas informações referentes às variáveis dos componentes de produção.

As variáveis avaliadas foram: altura de plantas e inserção da primeira espiga (por ocasião do florescimento pleno, foi medida a distância entre a superfície do solo e a inserção do pendão floral de oito plantas, e medida a distância entre a superfície do solo e a inserção da primeira espiga); diâmetro de colmo (aferido no primeiro entrenó da planta de milho, que compreende cerca de $5 \mathrm{~cm}$ acima do colo, utilizando-se paquímetro digital). O índice de clorofila foliar foi determinado utilizando-se o aparelho Chlorophyll Content Meter (CCM-200), em cinco plantas escolhidas, aleatoriamente, na área útil de cada parcela, sendo determinado em dois pontos distintos na folha, abaixo da primeira espiga, totalizando dez pontos de amostragem por parcela.

Para determinação do teor foliar de Si em plena floração, foram coletadas, aleatoriamente, as primeiras folhas, abaixo da primeira espiga, de cinco plantas na área útil de cada parcela. As folhas foram lavadas, acondicionadas em sacos de papel e levadas à estufa de ventilação forçada de ar, por 48 horas, a $65^{\circ} \mathrm{C}$, para secagem, sendo trituradas posteriormente. As análises foliares de Si foram feitas seguindo o método proposto por Korndörfer et al. (2004). O número de grãos por espiga foi determinado por ocasião da colheita, tendo sido coletadas cinco espigas, ao acaso, na área útil de cada parcela, sendo contados manualmente o número de grãos. A massa de 100 grãos foi calculada mediante três amostragens de 100 grãos, representativos de cada parcela experimental. A produtividade de grãos foi avaliada nas espigas contidas na área útil, colhidas manualmente. Após processamento, os grãos foram pesados e, posteriormente, foram calculados a produtividade em $\mathrm{kg} \mathrm{ha}^{-1}$ e os valores transformados para $13 \%$ de umidade.

Os dados foram submetidos a analise de variância. Quando constatada significância, empregou-se o teste Tukey, a 5\% de probabilidade, para comparação entre as médias de épocas de aplicação do silício. Para as doses de silício, empregou-se a análise de regressão, tendo sido a escolha das equações baseada na significância dos termos da regressão, no coeficiente de determinação e no comportamento biológico das características avaliadas.

\section{RESULTADOS E DISCUSSÃO}

A produtividade não diferiu ( $\mathrm{P}>0,05)$, com a aplicação de doses de Si, via foliar, em diferentes épocas (Tabela 1). De modo geral, apesar de o solo da área do experimento ser arenoso, extremamente intemperizado, com alto potencial de lixiviação, condições estas favoráveis à resposta das plantas à aplicação foliar de Si (Brady, 1992), esse efeito não foi observado.

No período de condução do experimento, as plantas de milho não sofreram nenhum estresse e a precipitação ocorreu bem distribuída (Figura 1), tendo um valor acumulado de $1429 \mathrm{~mm}$, no fim do experimento. Este valor foi superior ao mínimo exigido para a cultura do milho, situado entre 350 e 500 mm (Fancelli \& Dourado Neto, 2004). Esse é o provável motivo para que os tratamentos não surtissem efeito no experimento, pois o Si é um elemento que tem efeito mais pronunciado em ambiente de estresse para as plantas, seja ele biótico ou abiótico (Schmidt et al., 1999; Trenholm et al., 1999; Ma et al., 2001). Diversos autores indicam resultados positivos à aplicação de $\mathrm{Si}$ quando as plantas estão sujeitas a diferentes tipos de estresse, como por exemplo: estresse hídrico (Pulz et al., 2008), presença de $\mathrm{Al}^{3+}$ no solo (Wang et al., 2004) e ataque de pragas e doenças (Goussain et al., 2002), o que não foi verificado durante a condução do experimento. Isso pode explicar o fato de a aplicação foliar do Si não provocar incrementos na produtividade de grãos (Tabela 1), mesmo que o teor de Si na folha tenha apresentado aumentos até a dose de $260 \mathrm{~g} \mathrm{ha}^{-1}$ de Si (Figura 2).

Os resultados obtidos neste experimento assemelhamse aos observados por Mauad et al. (2003b), que, avaliando doses de Si em arroz, também não verificaram alterações na produtividade deste cereal.

Ao se analisar a menor produtividade alcançada no experimento (7981 kg ha-1), verifica-se sua superioridade em relação à média nacional da chamada $1^{\mathrm{a}}$ safra do ano agrícola 2006/2007 (aproximadamente $3851 \mathrm{~kg} \mathrm{ha}^{-1}$ ), estando, também, acima da média do Estado do Mato Grosso do Sul, que é de, aproximadamente, $5720 \mathrm{~kg} \mathrm{ha}^{-1}$, para a mesma época de cultivo (CONAB, 2007).

A massa de 100 grãos não diferiu em função da aplicação de doses de Si, via foliar, em diferentes épocas (Tabela 1). O Si proporciona vários benefícios para as plantas, destacando-se: melhor eficiência fotossintética e maior aproveitamento da água, dentre outros (Datnof et al., 2001). Seria de se esperar um maior enchimento de grãos com doses crescentes de $\mathrm{Si}$, o que não foi observado. O número de grãos por espiga (Tabela 1) não foi alterado, significativamente, em função da aplicação de doses de $\mathrm{Si}$, via foliar, em diferentes épocas.

Houve diferenças nos teores de Si nas folhas do milho $(\mathrm{P}<0,01)$, em função das doses de $\mathrm{Si}$, aplicadas por via 
foliar (Figura 2). O teor foliar de Si no milho apresentou comportamento quadrático (Figura 2); em doses superiores a 217,9 $\mathrm{g} \mathrm{ha}^{-1} \mathrm{o}$ Si aplicado pode não ter sido absorvido pelas folhas de milho, porém, sem reflexo negativo em produtividade (Tabela 1), o que concorda com as observações de Korndörfer et al. (1999b) que citam não existirem constatações de efeito tóxico do Si para as plantas, não havendo limites para aplicação desse fertilizante.

Por outro lado, segundo Korndörfer et al. (2006), plantas de milho acumulam teores de Si de 2,5 a 11,4 $\mathrm{g} \mathrm{kg}^{-1}$, portanto, o teor foliar de $\mathrm{Si}$ (Figura 2) está de acordo com o esperado, mesmo na testemunha, o que pode ter contribuído para a ausência de efeito, do Si aplicado, no incremento de produtividade (Tabela 1), por causa de as plantas apresentarem um teor adequado deste elemento.

Mauad et al. (2003b), testando diferentes doses de Si na cultura do arroz, verificaram que o aumento das doses proporcionou maiores teores foliares de $\mathrm{Si}$, o que não foi observado no presente experimento.

A aplicação em diferentes épocas não alterou os teores foliares de Si. Não existe época específica para aplicação foliar de Si, portanto, sugere-se que, futuramente, em novos ensaios, novas épocas e formas de aplicações sejam testadas..

Deren (2001) determinou que a aplicação de Si confere maior índice de clorofila às folhas; contrariamente, este índice (Tabela 2) não foi alterado em função da aplicação de diferentes doses de $\mathrm{Si}$ nem de diferentes épocas de aplicação, resultado diferente do de Savant et al. (1999) os quais verificaram que a aplicação de $15 \mathrm{t} \mathrm{ha}^{-1}$ de silicato aumentou o índice de clorofila em 78 e $65 \%$, em canaplanta e cana-soca, respectivamente.

A altura de plantas não foi influenciada por diferentes doses de $\mathrm{Si}$, nem por diferentes épocas de aplicação (Ta-

Tabela 1. Produtividade de grãos de milho, massa de 100 grãos e número de grãos por espiga em função do silício (Si) aplicado via foliar em diferentes épocas

\begin{tabular}{|c|c|c|c|}
\hline Tratamentos & Produtividade & Massa de 100 grãos & № de grãos por espiga \\
\hline Doses $(\mathbf{S i}) \mathrm{g} \mathrm{ha}^{-1}$ & kg ha $^{-1}$ & gramas & $\mathbf{N}^{\mathbf{0}}$ \\
\hline 130 & 8304,1 & 30,6 & 532,0 \\
\hline 260 & 8411,7 & 31,3 & 553,0 \\
\hline 390 & 8105,9 & 30,8 & 534,0 \\
\hline 520 & 8482,2 & 32,4 & 548,0 \\
\hline \multicolumn{4}{|l|}{ Épocas (E) } \\
\hline 2 folhas & 8894,5 & 30,8 & 538,0 \\
\hline 5 folhas & 7723,5 & 31,2 & 541,0 \\
\hline 8 folhas & 8360,0 & 31,8 & 546,0 \\
\hline Testemunha (T) & 9014,7 & 31,3 & 551,0 \\
\hline $\mathrm{CV}(\%)$ & 14,1 & 7,4 & 4,1 \\
\hline \multicolumn{4}{|l|}{ Teste F } \\
\hline $\mathrm{Si}$ & $\mathrm{ns}$ & ns & $\mathrm{ns}$ \\
\hline $\mathrm{E}$ & ns & $\mathrm{ns}$ & $\mathrm{ns}$ \\
\hline $\mathrm{Si} * \mathrm{E}$ & ns & ns & $\mathrm{ns}$ \\
\hline $\mathrm{T} *$ Fatorial & $\mathrm{ns}$ & $\mathrm{ns}$ & $\mathrm{ns}$ \\
\hline
\end{tabular}

n.s. = não significativo

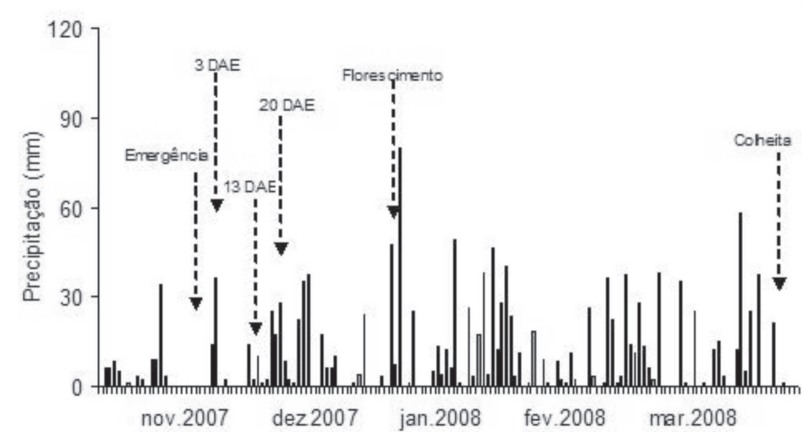

Figura 1. Valores diários de precipitação pluvial (mm), durante o período de novembro de 2007 a março de 2008, e datas de emergência, $3^{\circ}-13^{\circ}-20^{\circ}$ DAE (respectivamente $1^{\circ}, 2^{\circ}$ e $3^{\circ}$ épocas de aplicações dos tratamentos), florescimento e colheita. (Fonte: Chácara Beija Flor - Cassilândia - MS).

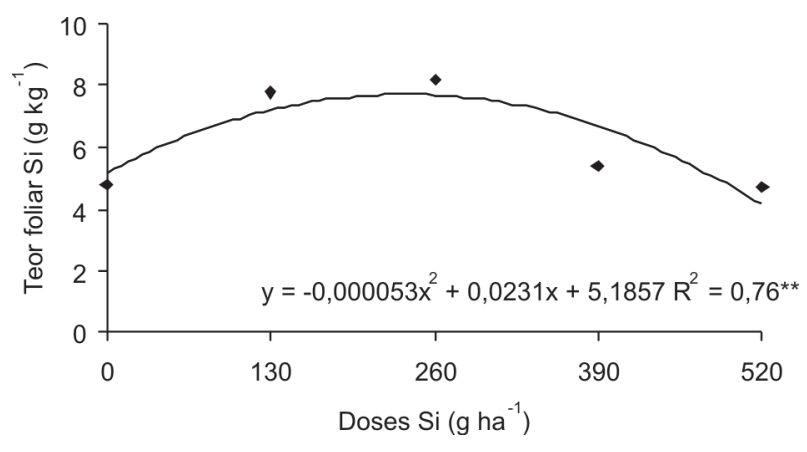

Figura 2. Teor foliar de silício ( $\mathrm{Si}$ ) em folhas de milho, em função do Si aplicado via foliar. ** - significativo a $1 \%$ de probabilidade

Rev. Ceres, Viçosa, v. 58, n.2, p. 262-267, mar/abr, 2011 
Tabela 2. Índice de clorofila foliar, médias de altura de plantas, altura de inserção da $1^{\mathrm{a}}$ espiga e diâmetro do colmo de plantas de milho, em função do Si aplicado via foliar em diferentes doses e épocas

\begin{tabular}{lcccc}
\hline Tratamentos & $\begin{array}{c}\text { Índice de } \\
\text { clorofila foliar }\end{array}$ & Altura da planta & $\begin{array}{c}\text { Altura de } \\
\text { inserção da 1a espiga }\end{array}$ & Diâmetro do colmo \\
\hline Doses $(\mathbf{S i}) \mathrm{g} \mathrm{ha}^{-1}$ & - & $\mathrm{m}$ & $\mathrm{m}$ & $\mathrm{mm}$ \\
\hline 130 & 45,9 & 2,2 & 1,0 & 25,2 \\
260 & 42,5 & 2,2 & 1,0 & 26,2 \\
390 & 45,1 & 2,2 & 1,0 & 25,2 \\
520 & 44,3 & 2,2 & 1,0 & 25,5 \\
\hline Épocas $(\mathbf{E})$ & & & 1,0 & 25,2 \\
\hline folhas & 42,8 & 2,2 & 25,5 \\
5 folhas & 45,8 & 2,2 & 1,0 & 25,8 \\
8 folhas & 44,8 & 2,2 & 1,1 & 25,4 \\
Testemunha $(\mathbf{T})$ & 48,1 & 2,2 & 7,5 & 5,5 \\
CV $(\%)$ & 14,1 & 3,9 & & $\mathrm{~ns}$ \\
\hline Teste F & & & $\mathrm{ns}$ & $\mathrm{ns}$ \\
\hline Si & $\mathrm{ns}$ & $\mathrm{ns}$ & $\mathrm{ns}$ \\
E & $\mathrm{ns}$ & $\mathrm{ns}$ & $\mathrm{ns}$ & $\mathrm{ns}$ \\
Si $*$ E & $\mathrm{ns}$ & $\mathrm{ns}$ & $\mathrm{ns}$ & \\
$\mathrm{T} *$ Fatorial & $\mathrm{ns}$ & $\mathrm{ns}$ & & \\
\hline
\end{tabular}

n.s. = não significativo

bela 2). A aplicação de Si normalmente estimula várias ações na planta, tais como: maior rigidez estrutural dos tecidos, por aumento da resistência mecânica das células, folhas mais eretas e diminuição do autossombreamento (Deren, 2001), mas nenhum fator direto que evidencie maior crescimento efetivo da planta.

A altura de inserção da primeira espiga (Tabela 2) também não foi influenciada pela aplicação de Si. Ainda, na Tabela 2, pode-se verificar que diâmetro de colmos não foi alterado, em função da aplicação de doses de Si, em todas as épocas.

\section{CONCLUSÃO}

A aplicação foliar de Si não influenciou o crescimento e a produção de plantas de milho. O teor máximo de 7,70 g $\mathrm{kg}^{-1}$ Si nas folhas de milho é obtido com a aplicação foliar de $217,9 \mathrm{~g} \mathrm{ha}^{-1}$ de Si.

\section{REFERÊNCIAS}

Brady NC (1992) The nature and properties of soil. $10^{\mathrm{a}}$ ed. New York, Edition Macmillan Publishing Co. 200p.

Camargo MS, Pereira HS, Korndörfer GH, Queiroz AA \& Reis CB (2007) Soil reaction and absorption of silicon by rice. Scientia Agrícola, 64:176-180.

Conab (2007) Companhia nacional de abastecimento. $1^{\circ}$ Levantamento OUT/2007. Disponível em: <http://www.conab.gov.br/ conabweb/>. Acessado em: 23 de julho de 2008.

Costa RR, Moraes JC \& Costa RR (2009) Interação silícioimidacloprid no comportamento biológico e alimentar de Schizaphis graminum (Rond.) (Hemiptera: Aphididae) em plantas de trigo. Ciência e Agrotecnologia, 33:455-460
Datnoff LE, Snyder GH \& Korndörfer GH (2001) Silicon on Agriculture. Amsterdam, Elsevier Science. 424p.

Deren C (2001) Plant genotypes, silicon concentration and silicon related responses. In: DATNOFF LE, SNYDER GH \& KORNDÖRFER GH (Eds.) Silicon in Agriculture. Amsterdam, Elsevier Science. p.149-158.

EMBRAPA Centro Nacional de Pesquisa de Solos (1999) Sistema brasileiro de classificação de solos. Brasília, EMBRAPA.412 p.

Epstein, E (2001) Silicon in plants: Facts vs. concepts. In: Datnoff LE, Snyder GH, Korndörfer GH (Eds.) Silicon in Agriculture. Amsterdam, Elsevier Science. p.1-15.

Fancelli AL \& Dourado Neto D (2004) Produção de milho. Guaíba, Agropecuária. 360p.

Goussain MM, Moraes JC, Carvalho JG, Nogueira NL \& Rossi ML (2002) Efeito da Aplicação de Silício em Plantas de Milho no Desenvolvimento Biológico da Lagarta-do-Cartucho Spodoptera frugiperda (J.E.Smith) (Lepidoptera: Noctuidae). Neotropical Entomology, 31:305-310.

Korndörfer GH, Arantes VA, Corrêa GF \& Snyder GH (1999a) Efeito do silicato de cálcio no teor de silício no solo e na produção de grãos de arroz de sequeiro. Revista Brasileira de Ciência do Solo, 23:623- 629.

Korndörfer GH, Coelho NM, Snyder GH \& Mizutani CT (1999b) Avaliação de métodos de extração de silício em solos cultivados com arroz de sequeiro. Revista Brasileira de Ciência do Solo, 23:101-106.

Korndörfer GH (2004) Análise de silício: solo, planta e fertilizante. Uberlândia, GPSi-ICIAG-UFU (Boletim Técnico, 02). 39p.

Korndörfer GH (2006) Elementos benéficos. In: Fernandes MS (Eds.) Nutrição mineral de plantas. Viçosa, Sociedade Brasileira de Ciência do Solo. p.355-374.

Ma JF, Miyake Y \& Takahashi E (2001) Silicon as a benefic element for crop plants. In: Datnoff LE, Snyder GH \& Korndorfer GH (Eds.) Silicon in agriculture. Amsterdam, Elsevier. p.17-39. 
Mauad M, Crusciol CAC, Grassi Filho H \& Corrêa JC (2003a) Nitrogen and silicon fertilization of upland rice. Scientia Agrícola, 60:761-765.

Mauad M, Grassi Filho H, Crusciol CAC \& Corrêa JC (2003b) Teores de silício no solo e na planta de arroz de terras altas com diferentes doses de adubação silicatada e nitrogenada. Revista Brasileira de Ciência do Solo, 27:867-873.

Madeiros LB, Vieira AO \& Aquino BF (2009) Micronutrientes e silício nas folhas da cana-de-açúcar: escória siderúrgica aplicado no solo. Engenharia Ambiental, 6:27-37.

Melo SP, Korndörfer GH \& Korndörfer CM (2003) Silicon accumulation and water déficit tolerance in Brachiaria grasses. Scientia Agricola, 60:755-759.

Pereira HS, Korndörfer GH, Vidal AA \& Camargo MS (2004) Silicon sources for rice crop. Scientia Agricola, 61:522-528.

Pulz AL, Crusciol CAC, Lemos LB \& Soratto RP (2008) Influência de silicato e calcário na nutrição, produtividade e qualidade da batata sob deficiência hídrica. Revista Brasileira de Ciência Solo, 32:1651-1659
Raij B Van, Cantarella H, Quaggio JA \& Furlani AMC (1997) Recomendação de adubação e calagem para o estado de São Paulo. 2 ed. Campinas, IAC. 285p. (IAC, Boletim técnico, 100).

Savant NK, Korndörfer GH, Snyder GH \& Datnoff LE (1999) Silicon Nutrition and Sugarcane Production: A review. Journal of Plant Nutrition, 12:1853-1903.

Schmidt RE, Zhang X \& Chalmers DR (1999) Response of ptotosynthesis and superoxide dimutase to silica applied to creeping bentgrass grown under two fertility levels. Journal of Plant Nutrition, 22:1763-1773.

Trenholm LE, Duncan RR, Carrow RN \& Snyder GH (1999) Influence of silica on growth, quality, and wear tolerance of seashore paspalun. Journal of Plant Nutrition, 22:1763-1773.

Wang Y, Stass A \& Hors TW (2004) Apoplastic Binding of Aluminum Is Involved in Silicon-Induced Amelioration of Aluminum Toxicity in Maize. Plant Physiology Preview, 136:3762-3770. 